\title{
Analysis of additional hotel services in the international luxury hotels - a case-study from Budapest
}

\author{
Katalin JUHÁSZ-DÓRA \\ Corvinus University of Budapest, Budapest, Hungary \\ katalin.juhaszdora@gmail.com
}

\begin{abstract}
The investigation of additional services from the aspect of local embeddedness is a novelty in the academic literature related to the tourism and hotel industry. The primary function of hotels is to provide accommodation and other services for the hotel-guests. Secondarily, they may also offer complementary-services and a community space for the city-residents and for nonhotel guests. Due to the globalization, the change in the consumer behaviour and global firms, the question of location and local resources are becoming more and more significant especially in the case of international hotel chains. The international hotel company is a member of a hotel market at a specific location, and it is surrounded by a sociological environment, local people, culture and traditions which have an impact on the competitiveness of the hotel. The author explains the results with the application of the multidimensional scaling model, finding answers for the questions in which ways the local embeddedness can have an effect on the competitiveness of a hotel based on a case-study carried out in a five-star hotel (member of an international chain) of Budapest in 2016.
\end{abstract}

Keywords: additional hotel services, local embeddedness, international hotel chains, hotel competitiveness, multidimensional scaling model

\section{Introduction}

The following pilot-study investigates how the vivid social life of the 21st century can reborn in the $21^{\text {st }}$ century in an iconic grand hotel of the city by the means of focusing on the complementary services at a specific location. This concept is not only significant from a sociological perspective, but it also points out its economic effect. It is assumed that on the long-term it has a positive effect on hotel competitiveness.

The primary function of hotels is to provide accommodation and other services for the hotel-guests. Secondarily, they may also offer complementary-services and a community space for the city-residents and for non-hotel guests. Hotel-life takes place usually in the hotel lobby and in the different outlets which offer complementary services (restaurant, bar, shop, beauty salon, spa, etc.) on the ground floors. In the past, the hotel lobby was a central meeting point, a so-called public arena, where a particular kind of urban sociality flourished in the 21st century. One reason for this is the fact, that time the number of restaurants, event halls and social places were not as high as today. On one hand, the luxurious hotels functioned as second home for the aristocrats; on the other hand, they provided space for high-class events and gatherings providing great spaces and luxurious service. Grand Hotels were iconic landmarks of the cities, where also the invited residents were pleased to join on some special occasions.

In addition to their primary function of providing accommodation for tourists (local and also foreign guests), due to a change in consumer behaviour and also due to profitability reasons hotel companies recognized business possibilities in offering complementary services. If the relationship of hotels and cities is investigated, it can be stated that there are iconic hotel buildings which not only function as places providing accommodation for tourists, but represent a social meeting space for the residents and the tourists, a business place, to create a comfortable environment and pleasant ambience for the tourists and for the residents at the same time. 
Conrad Nicholson Hilton, the founder of Hilton company highlighted one of the most dominant factor of competitiveness in the beginning of the $21^{\text {st }}$ century: "Location, location, location is everything!". Hotel expert focused on the importance of destinations, because the aim of guest travels is usually visiting a destination. Due to a change in consumer behaviour and the desire of the guests for unique experience the question of competitiveness is a very important factor in decision-making. A number of examples exist also from the $21^{\text {st }}$ century, innovative processes from the hotel industry, hotels assets which aim to target the citizens as well. These hotels in most cases are located in the city-centres and from an architectural point of view, it can be stated that the facilities which are popular for the citizens as well are located in the hotel-front so that the citizens can enter to the specific shop or any other special facility without entering the hotel lobby. Some hotels use their special facility as a competitive advantage and only offer an outsourced place to rent in the back of the hotel to force the citizens to go through the lobby, meet the hotel-guests, creating a vivid-hotel life contributing to the style and ambience of the hotel. Hotels today are much more than temporary homes for tourists, they are full of life. Hotel lobbies are social meeting places for the local citizens and foreign tourists. Therefore hotels following this practice can be described as locally embedded hotels. Community spaces of locally embedded hotels reflect the unique selling points of the city, the history, the local values and the traditions of the local culture. These places create a platform where co-creation and interaction can be present between the foreign employees, the local employees, the foreign guests and between the local guests also. These hotels may function as social hubs of the city offering high-level unique service for all guests.

First, a literature review on hotel competitiveness and factors affecting hotel competitiveness will be presented. Second, complementary hotel services and local embeddedness will be investigated from the aspect of competitiveness.

\section{Literature review}

\section{Competitiveness in the hotel industry}

A number of academic studies are available focusing on hotel competitiveness and there is no consent on the definition of hotel competitiveness, but there are debates on the most significant factors of competitiveness. Productivity is a key element of hotel competitiveness. A competitive firm has certain advantages given by the key factors it possesses and its rivals don't (for instance, understanding the requirements of the consumers, a brand and innovation). According to Ioncica et al. (2006), the concept of competitiveness is subdivided on two sub-concepts: comparative advantage and competitive advantage. In terms of business segment, companies can create relative competitive advantage and possess unique resources. Competitiveness has different applications when applied to different levels and the common purpose is to achieve a beneficial position through the establishment of competitive advantage.

As tourism and hotel industry prospers in the global economy, the number and variety of accommodation possibilities is increasing, the desire of the tourists for discovering and visiting new destinations is also increasing and the future guests are provided several online and offline platforms to make decisions about which is the most adequate hotel which fits their needs and suits their expectations. Competitiveness becomes a more significant question than ever. Competitiveness can be observed as an evolution of the concept from static competitiveness, during which the competitive advantage is given by an endowment with technical factors, to the dynamic one, whose key factors are technical progress, salary raises and modern management methods. In 
this case competitive advantage surpasses the economic dimensions and starts to include the increase of the country's financial and productive forces, education, safety and standard of living. Competitiveness is also associated with the idea of success, of long term survival and it does not characterize only the economic life but the effects can be also felt in the social domain.

Nowadays Corporate Social Responsibility (CSR), the social and environmental responsible activities of the firms is more and more significant. CSR is a concept which possesses economic, social and environmental dimensions. Nowadays the international organizations pay the greatest attention to increase the quality of working environments, to use forms of renewable energy and to fight against corruption. The fact that the larger companies not only take out but give back something for the citizens is very important in the case of CSR. With the appropriate implementation and application of CSR, the improvements can be sustainable on long-term.

Economic effect of hotels is easy to understand, hotels work through markets, the aim to be profitable is evident for them. Revenue and yield management play a significant role in reaching the highest revenue with optimal utilization. In other words yield and revenue management aims to conduct an active price changing policy at the market which finally results in the increase of the revenue and occupancy. These results can be reached by the exact analysis of the demand of the guest segment, defining the appropriate target market and the positioning of the services. This is the task of the hotel marketing, among these the hotels have to pay attention to the feedback of the guests which provide long-term sustainability and guest loyalty. Hotels pay an important role in the economy of a destination of a country with the multiplicator effect employment places are created, foreign capital flows in and the tourist are spending, using the facilities and services of the region.

Figure 2. Analysis of the complementary services in the investigated hotel
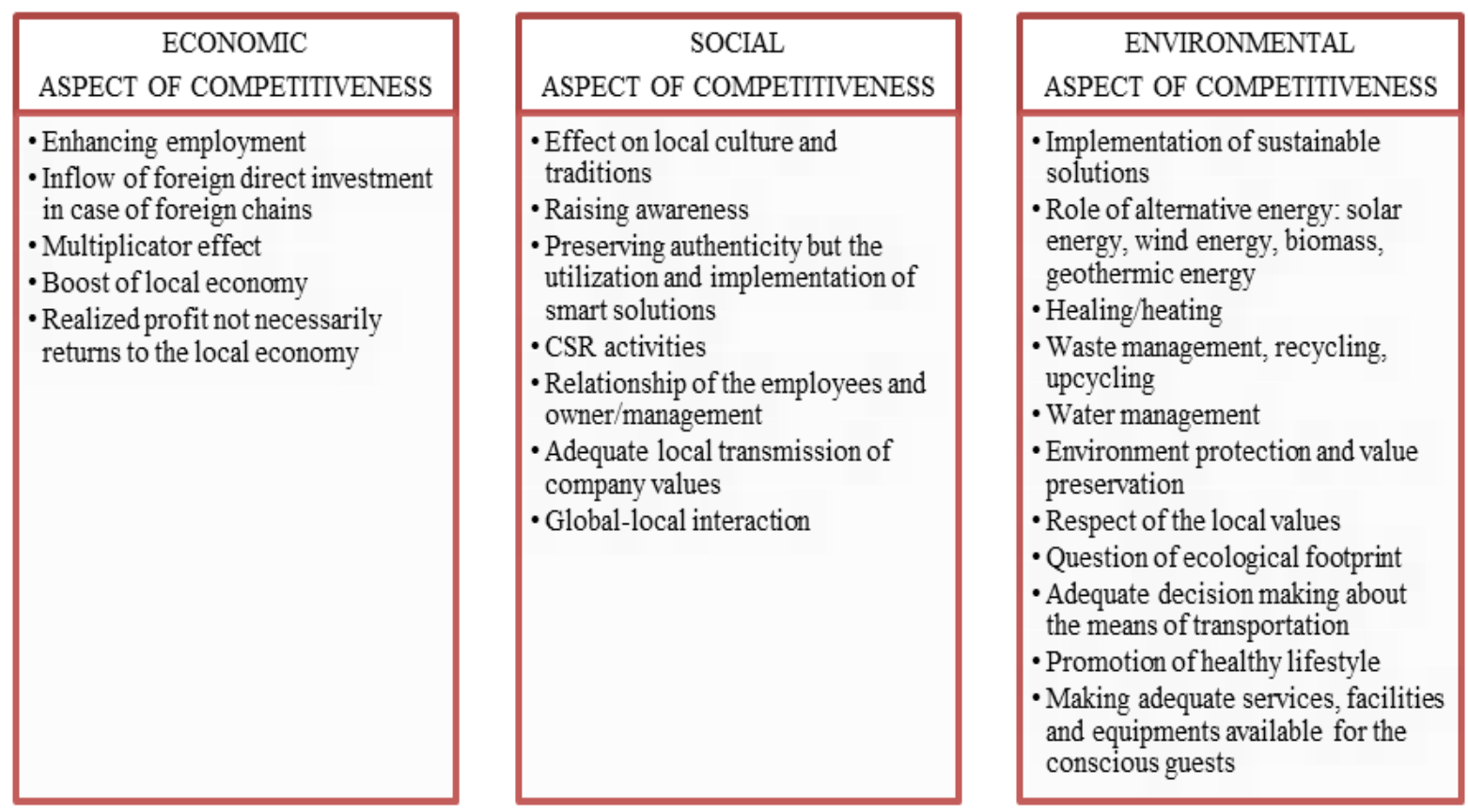

Source: Research results based on the questionnaire.

\section{Local embeddedness in the hotel industry}

The investigation of local embeddeadness is a novelty in the academic literature related to tourism and the hotel industry. From the aspect of sociology, Karl Polanyi 
investigated embeddedness first in 1944. Due to the globalization, the change in the consumer behaviour and global firms, the question of location and resource-based sources are becoming more and more significant especially in the case of international hotel chains. The international hotel company is a member of a hotel market at a specific location, and it is surrounded by a sociological environment, local people, culture and traditions which have an impact on the competitiveness of the hotel according to the assumption of the author. Based on various examples, it can be stated that tourists and residents in day-to-day contexts and life, has today become a design parameter for the tourist experience, giving rise to new and emerging forms of urban and tourist organisation together (Cipoletti, 2014). Economic sociology has established the interdependencies between economic and social structures using the notion of embeddedness of the former in the latter (Brailly et. al., 2016). In the area of economic sociology a number of researches has exposed the importance of social networks in markets, indicating the relevance of relational structures for the emergence of economic activities (Granovetter and Swedberg, 1992, Brass et. al. 2004). Granovetter's (1985) article on embeddedness is famous for asserting at a high level of generality that economic phenomena take place in social structures and are shaped by social networks. Individuals do not act as atoms in social life, their behaviour is not entirely defined by macro-structures, and their actions depend on a relational context. Bathelt and Schuldt (2008) called global pipelines the long distance partnerships between companies that globalized markets require. Behind each partnership a different relationship is represented. Behind each partnership between companies, there are always interindividual ties (Gulati, 1995). According to the literature, the definition embeddedness, is identified as the nature, depth, and extent of an individual's ties into the environment, has recently been commented upon as a configuring element of general business process (Whittington, 1992; Uzzi, 1997; Dacin et al., 1999). In the last decade embeddedness from economic aspect in the academic literature is connected to performance, competition, innovation and firm embeddedness (Dima et al., 2016, Dima and Ghinea, 2016).

Another aspect has to be investigated in cases of embeddedness and analysis of networks, the question of outsourcing. There has been a long tradition of hotels providing both food and accommodation for the travellers as part of the hotel product. In the recent years, several hotel restaurants were not profitable, hotel restaurants have become support amenities to what has come to be seen as the core business of accommodation. Two significant trends have emerged (Hemmington and King, 2000). On the one hand, the independent restaurant sector has become highly competitive and has focused on meeting the needs of the market with creative and innovative branded restaurant concepts (Casper, 1995). Hotel restaurants, on the other hand, are generally perceived to fall behind at the competition and to have lost touch with their customers (Hallam and Baum, 1996). Dining at a restaurant which is operated at the hotel is sometimes not fancy, and sometimes standardised, that is the reason the guests go out of the hotel and try some local restaurants. Another trend which led to the outsourced management of the food and beverage outlets is the continuous need to maximize cashflow which finally led to close scrutiny of the profit performance of every square metre of the hotel spaces. As a result, the poor economic performance led to an increased attention to the food and beverage bottom line. The outsourcing of the hotel restaurants is becoming increasingly common, particularly, as hoteliers become more comfortable with the presence of restaurant brands in their properties and as restaurateurs become more competitive in the terms they are prepared to agree 
(Hemmington and King, 2000).

\section{Different aspects of competitiveness}

As tourism and hotel industry prospers in the global economy, the number and variety of accommodation possibilities is increasing, the desire of the tourists for discovering and visiting new destinations is also increasing and the future guests are provided several online and offline platforms to make decisions about which is the most adequate hotel which fits their needs and suits their expectations. Competitiveness becomes a more significant question than ever. Competitiveness can be observed as an evolution of the concept from static competitiveness, during which the competitive advantage is given by an endowment with technical factors, to the dynamic one, whose key factors are technical progress, salary raises and modern management methods. In this case competitive advantage surpasses the economic dimensions and starts to include the increase of the country's financial and productive forces, education, safety and standard of living. Competitiveness is also associated with the idea of success, of long term survival and it does not characterize only the economic life but the effects can be also felt in the social domain.

Nowadays Corporate Social Responsibility (CSR), the social and environmental responsible activities of the firms is more and more significant. CSR is a concept which possesses economic, social and environmental dimensions. Nowadays the international organizations pay the greatest attention to increase the quality of working environments, to use forms of renewable energy and to fight against corruption. The fact that the larger companies not only take out but give back something for the citizens is very important in the case of CSR. With the appropriate implementation and application of CSR, the improvements can be sustainable on long-term.

Economic effect of hotels is easy to understand, hotels work through markets, the aim to be profitable is evident for them. Revenue and yield management play a significant role in reaching the highest revenue with optimal utilization. In other words yield and revenue management aims to conduct an active price changing policy at the market which finally results in the increase of the revenue and occupancy. These results can be reached by the exact analysis of the demand of the guest segment, defining the appropriate target market and the positioning of the services. This is the task of the hotel marketing, among these the hotels have to pay attention to the feedback of the guests which provide long-term sustainability and guest loyalty. Hotels pay an important role in the economy of a destination of a country with the multiplicator effect employment places are created, foreign capital flows in and the tourist are spending, using the facilities and services of the region.

\section{Research problem and methodology}

The investigated luxury Hotel in Budapest is operated and managed based on the standards of an International Hotel Chain. The revenue system this luxury chain is applying, does not differentiate the revenue received from the non-house guests and inhouse guests in the case of the complementary services. On the guest receipts and during the controlling process of the analysis of the guest expenditure 3 different payment groups are formed: cash, credit card or room charge.

Unfortunately this type of data recording does not make it possible to analyse the expenditure of the non-house guests. When predictions are made, the controllers usually regard the cash-receipts non-house guests. They check the payer member based on the provided credit-card data, investigate, if the person is a hotel guest, and make a decision 
based on this result. But this analysis is neither totally correct. Despite the fact, that in a hotel room there are two guests, the room is only recorded under one name. The other person of the room can settle the bill for the restaurant consumption, and then this amount of revenue will be regarded non-house guest revenue falsely. In the case of corporate guests the revenue analysis is not correct. In the case of corporate guests, the rooms are usually financed by their firms and the complementary services are paid by themselves. The hotel managers are aware of this fact. Their opinion is that until the revenue received from the complementary services is not as high as the revenue received from events, this data will not be recorded separately.

The author assumes, that in the case of grand hotels, luxurious hotels which offer a great variety of services, boast with large, spacious events rooms, possesses community and meeting spaces, can offer services not only for business, but for leisure guests; this data should be correctly recorded. Definitely, this revenue will never compete with the revenue gained from the events, but these facts should be considered to handle low-season revenue for example. This could provide a solution to aim the loyal citizens with unique services; but first of all, the question has to be investigated, if a nonhouse guest segment really exists, who visits the hotel.

Due to the above mentioned reasons, in-house business data describing precisely the results for the research questions could not be obtained, therefore a questionnaire was applied.

From September 2016, the author started to build up the questionnaire, it was rewritten and edited several times according to the consultation with the hotel managers and the head of the different outlets. There is another interesting fact during the investigation of this hotel. Some of the outlets offering complementary services are outsourced, which means that they are not under the operation of the hotel management, a different firm operates these places. Due to this fact, altogether 5 types of questionnaires were formed. The different type of questionnaires were distributed at the different hotel outlets and the guests had the possibility to provide responses during a period of 8 weeks, from 24 October until 18 December, 224 responses were received out of which 223 can be regarded valid. The questionnaires were divided into department-specific and general questions.

The author assumes, that the investigated Hotel in Budapest, a more than 120year-old grand hotel (boasting with than 300 rooms) is a locally embedded hotel, due to the fact, that it offers its services not only for the hotel guests, but also invites a great number of non-hotel guests (and local citizens), who regularly visit the hotel because of its high-level and unique services.

The research question focuses on the investigation of the relationship between these complementary services analyses if they can be grouped or sorted based on any statistical method.

\section{Research results}

In the case of this research the best applicable method for finding the answer for research question is ALSCAL. ALSCAL is a nonmetric multidimensional scaling process with several individual-differences options. This method attempts to find the structure in a set of distance measures between objects or cases. This task is accomplished by assigning observations to specific locations in a conceptual space (usually two- or threedimensional) such that the distances between points in the space match the given dissimilarities as closely as possible. In many cases, the dimensions of this conceptual space can be interpreted and used to further analyse the data. The main advantage of 
this is that it is suitable for any type of two- or three-way data, that may be measured at the nominal, ordinal, interval or ratio level of measurement. ALSCAL permits the analysis of an unlimited number of points or subjects in as many as six dimensions.

Distance measurement has a central role in multidimensional scaling. At the beginning of the analysis the distances between pairs of items should be measured. These distances can be compared to other distance values between pairs of items in the analysis that ca be calculated in a low-dimensional coordinate system. The original distance may be proximity or similar values, but the distances are usually Euclidean distances.

The ALSCAL model was an adequate process which provides statistically acceptable answers and also gives an adequate answer for the research questions. The guests who have ever stayed or currently stay in the hotel can be categorised into four groups based on the complementary services they choose: who visit the restaurants, who take part at events, who sleep at the hotel and the other group of complementary services (these are not used as many times as events and restaurants). Who stay for a night at the hotel can go to the restaurant or take part at an event as well, but usually who attends an event, does not go to the restaurant. These two services are usually requires separately. Guests who attend events or visit the restaurant can both use any of the other complementary services. Some of these services were grouped, now this group is further analysed with ALSCAL. The stress factor is 0.01709 which is acceptable. The number of the variables investigated in this case were 9. From the 9-dimension space a 2 -dimension space can be created with the error of $1,79 \%$.

In the cases of the dimension of the complementary services, which were not as much used as the other services can be made further categories by the means of ALSCAL. Business and leisure guests can be divided again into sub-categories, maybe a gender division, "ladies" and "men" services can be differentiated. Those who visit the bar and the flower shop is a third group (Fig. 2.).

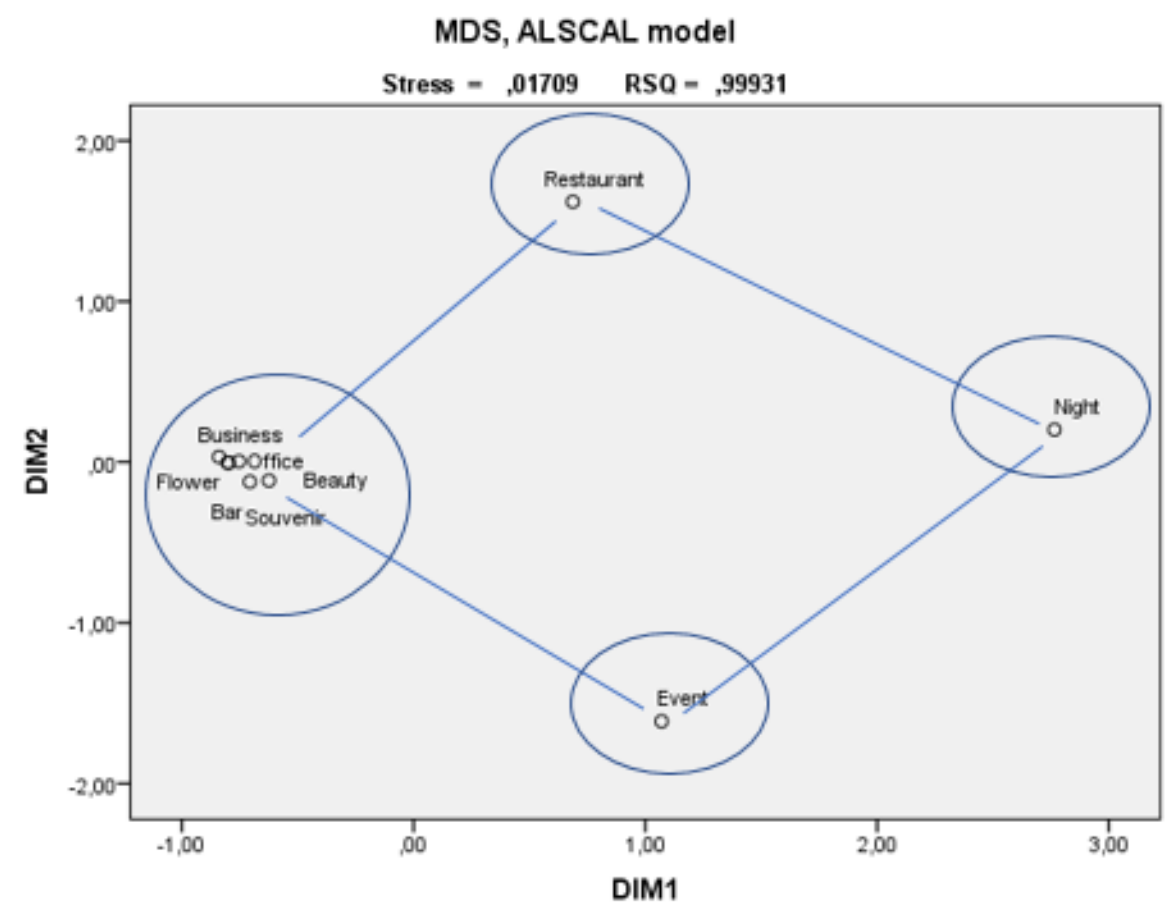

Figure 2. Analysis of the complementary services in the investigated hotel

Source: Research results based on the questionnaire.

The complementary services of other hotels were analysed as well. In this case three categories were formed. Different segment visits the bars, the complementary 
services and the leisure services. Based on these results, it can be concluded that business and corporate guests usually spend on complementary services higher than leisure guests.

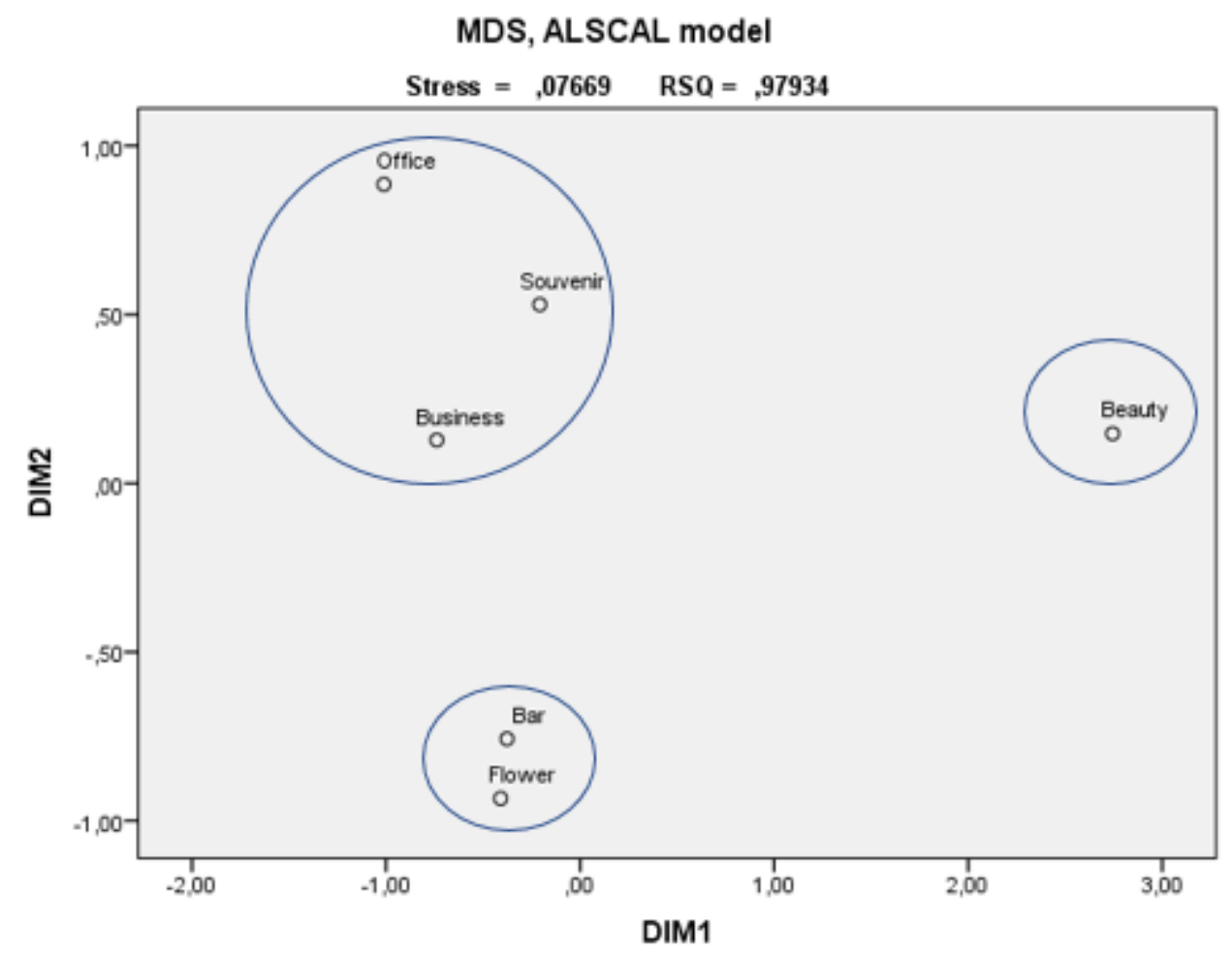

PICBE | 891

Figure 3. Analysis of the complementary services in the investigated hotels (Group of Business, Bar, Flower, Office and Souvenir group)

Source: Research results based on the questionnaire

In the cases of the dimension of the complementary services, which were not as much used as the other services can be made further categories by the means of ALSCAL. Business and leisure guests can be divided again into sub-categories, maybe a gender division, "ladies" and "men" services can be differentiated. Those who visit the bar and the flower shop is a third group (Fig. 3.).

\section{Conclusion}

Based on the assumptions of the author, and the investigated grand hotel is a locally embedded hotel, due to the fact, that it offers its services not only for the hotel guests, but also invites a great number of non-hotel guests (and local citizens), who regularly visit the hotel because of its high-level and unique services. Being locally embedded in the environment from the aspect of sociology it can be concluded that on the long term this fact has an effect on the competitiveness of the hotel.

From September 2016, the author started to build up the questionnaire, and with the help of it asked the opinion of the guests on complementary hotel services. The different types of questionnaires were collected from the different hotel departments. In this study not the whole data-set was analysed, only a part of them managed, related to answer the research questions.

In the pilot-study the author aimed to answer the research question (categorisation and grouping of the hotel services) with the application of the ALSCAL (multidimensional scaling model). All the assumptions were true in the case of this investigated hotel, but to be able to define the complementary services and their 
presence, revenue derived from them and to be able to make long-term statements on competitiveness, a more representative data-set should be collected.

This pilot-study was a great challenge. The test-questionnaire has to be re-edited and made simpler to be able to receive more answers from the respondents. The outletspecific questions should be re-organised as well, and more different variables should be listed in the cases of different departments. A whole-year analysis would be a very interesting data-set to analyse comparing it with the results of other luxury hotels.

Receiving data from hotels managed by international chains is a great challenge, but the author would like to focus on it, to be able to receive valid and representative data-set for the final dissertation from other hotels, too.

\section{References}

Bathelt, H., Schuldt, N. (2008). Temporary face-to-face contact and the ecologies of global and virtual buzz, Eur. Plan. Stud. 18, 1957-1974.

Brailly, J., Favre, G., Chatellet, J., Lazega, E. (2016). Embeddedness as a multilevel problem: A case-study in economic sociology, Social Networks (44) 319- 333.

Casper, C. (1995). Confirmed reservations, Restaurant Business, 94 (17), 109-18.

Cipolletti, S. (2014). Tourism Spaces: The New Experience Design. Almatourism-Journal of Tourism, Culture and Territorial Development, 5(1), 92-105.

Dima, A. M., Ghinea, V. (2016). Conference: 12th European Conference on Management, Leadership and Governance (ECMLG) Location: Natl Univ Polit Studies \& Publ Adm, Coll Management, Bucharest, ROMANIA Date: November 10-11, 2016.

Dima, A.M., Hadad, S., \& Cantaragiu, R. (2016). A conceptual analysis of businessuniversity knowledge transfers in the energy field. ENERGY, CLIMATE CHANGE AND SUSTAINABILITY, 201-207.

Dacin, M.T., Ventresca, M.J., Beal, B.D. (1999). The embeddedness of organisations: dialogue and directions. J.Manage. 25 (3), 317-353.

Granovetter, M.S. (1985). Economic Action and Social Sctructure: the problem of embeddedness, Am. J. Sociol. 91, 481-510.

Granovetter, M.S. , Swedberg, R. (eds) . (1992). The Sociology of Economic Life. Westview Press, Boulder, CU.

Gulati, R. (1995). Does familiarity breed trust? The implications of repeated ties for contractual choices in alliances. Acad. Manage. J. 38 (1), 85-112.

Hallam, G. and Baum, T. (1996). Contracting out food and beverage operations in hotels: a comparative study of practices in North America and the United Kingdom, International Journal of Hospitality Management, 15(1), 41-50.

Hemmington, N., King, C. (2000). Key dimensions of outsourcing hotel food and beverage services, International Journal of Contemporary Hospitality Management, 12(4), 256-261.

Ioncica, M., Draghici, M., Petrescu, C., Ioncica, D. (2009). Services specialization (a possible index) and its connection with competitiveness: the case of Romania, The Service Industries Journal, 30(12) , 2023-2044

Polanyi, K. (1944). The Great Transformation Visual methods: Using photographs to capture customers' experience with design Cornell Hotel and Restaurant Administration Quarterly, 48(2), 121-144.

Uzzi, B. (1997). Social structure and competition in interfirm networks: the paradox of embeddedness. Adm. Sci.

Whittington, R. (1992). Putting Giddens into action: social systems and managerial agency. J. Manage. Stud. 29(6), 693-713. 